\title{
1 Evolutionary and domestication history of Cucurbita (pumpkin and squash) \\ 2 species inferred from 44 nuclear loci
}

3

4 Heather R. Kates ${ }^{1,2}$, Pamela S. Soltis ${ }^{1,2}$, Douglas E. Soltis ${ }^{1,2,3}$

5

6 Author Information

7 Addresses:

81 Univ Florida, Univ Florida, Genet Inst, Gainesville, FL 32611 USA

92 Univ Florida, Florida Museum Nat Hist, Gainesville, FL 32611 USA

103 Univ Florida, Dept Biol, Gainesville, FL 32611 USA

11 Author for correspondence:

12 Heather R. Kates

13 email: $\underline{\text { hkates@ufl.edu }}$

14 telephone: 352-273-1976

15 Tables: 1; Figures: 6 (Figs. 1-5 color)

16 Appendix A: Supplementary material

17 Tables: 2; Figures: 92

\section{Abstract}

Phylogenetics can facilitate the study of plant domestication by resolving sister relationships

21 between crops and their wild relatives, thereby identifying the ancestors of cultivated plants.

22 Previous phylogenetic studies of the six Cucurbita crop lineages (pumpkins and squashes) and their wild relatives suggest histories of deep coalescence that complicate uncovering the genetic

24 origins of the six crop taxa. We investigated the evolution of wild and domesticated Cucurbita

25 using the most comprehensive and robust molecular-based phylogeny for Cucurbita to date based on 44 loci derived from introns of single-copy nuclear genes. We discovered novel

27 relationships among Cucurbita species and recovered the first Cucurbita tree with well-

28 supported resolution within species. Cucurbita comprises a clade of mesophytic annual species

29 that includes all six crop taxa and a grade of xerophytic perennial species that represent the 
hypothesize that the magnitude of domestication bottlenecks varies among Cucurbita crop

32 lineages. Our phylogeny clarifies how wild Cucurbita species are related to the domesticated taxa. We find close relationships between two wild species and crop lineages not previously identified. Expanded geographic sampling of key wild species is needed for improved understanding of the evolution of domesticated Cucurbita.

Keywords: Cucurbita (pumpkin), domestication, evolution, phylogeny, single-copy nuclear genes, crop wild relatives

\section{Introduction}

The domestication of Cucurbita (squashes and pumpkins) is among the earliest on record, with archaeological evidence indicating that Cucurbita species were used by humans as early as ca. 10,000 B.P. (Smith, 2006). With an incredibly rich and long history of domestication and cultivation, Сисurbita crops are unrivalled in fruit morphological diversity and their wide range of adaptation to cultivation. Among all plants cultivated for edible fruit, squashes and pumpkins have the most dramatic increase in fruit size compared with their wild relatives (Savage et al., 2015). taxa exhibit different adaptations to cultivation (Nee, 1990). For example, C. ficifolia (figleaf gourd) is adapted to cool temperatures and short days whereas C. moschata (butternut squash, Seminole pumpkin, canned pumpkin, and others) grows best in the humid tropics. Cucurbita pepo ssp. pepo (jack-o-lantern pumpkin, zucchini, summer squash, spaghetti squash,

57 (Nee, 1990). The multiple domestication events from diverse wild ancestors in Cucurbita serve as replicates of domestication and therefore make Cucurbita an especially valuable system in which to study crop evolution.

Cucurbita $(2 n=40)$ comprises 14 species, with six subspecies and two wild varieties (Nesom, 2011) (Table 1). The wild taxa occupy diverse elevational and latitudinal habitats 
ranging from the Midwestern United States to southern Argentina, with a center of diversity in Mexico (Fig. 1). Five of the wild Cucurbita species are xerophytic perennials that occur in Mexico and the southwestern United States; seven wild species are mesophytic annuals that occur in Mexico, the southeastern and southcentral United States, and Central and South America (Nee, 1990). The mesophytic annuals are apparently the result of a very recent radiation ( 7 mya) from a common ancestor in Central or South America (Schaefer et al., 2009).

The six Cucurbita crop lineages are hypothesized to be of independent origin from different wild ancestors in different geographic regions (Nee, 1990) (Fig. 1). Whereas the origins of many similarly valuable crops (e.g. common bean: Gepts, 1996; kiwi: Atkinson et al., 1997; cassava: Olsen et al., 1999; pea: Jing et al., 2011; eggplant: Meyer et al., 2012) have been identified, the ancestors of four of the six Cucurbita crop lineages, including the two most economically important, C. pepo ssp. pepo and C. moschata, are still unknown, despite repeated efforts to identify them (e.g. Sanjur et al., 2002; Zheng et al., 2013; Kistler et al., 2015).

Phylogenetic studies of crops and their wild relatives are a necessary crucial first step in investigating the genetic basis of domestication, as interpretation of any phenotype in an evolutionary context requires a phylogeny (Kellogg \& Birchler, 1993; Olsen \& Purugganan, 2002; Caicedo \& Schaal, 2004; Collins et al., 2005). Furthermore, resolving sister relationships between crops and their wild relatives (e.g. Hoffman et al., 1986; Mayer \& Soltis, 1994) is key to identifying the ancestors of cultivated plants. Moreover, studies that include sufficiently broad geographic sampling can point to geographic regions where close relationships between wild populations and the domesticate suggest a center of domestication (e.g. Smykal et al., 2010; Huang et al., 2012; Meyer et al., 2012).

Studies of evolutionary relationships within domesticated groups have contributed greatly to our understanding of the history and origin of cultivated plants. For example, researchers argued for decades about whether the distinctive architecture of maize could be the product of a single vs. multiple origins (e.g. Wilkes, 1977; Doebley \& Iltis, 1980; Doebley, 1990). However, a genetic study of relationships within Zea (Matsuoka, 2002) settled this debate by showing that cultivated maize is most closely related to teosinte from Oaxaca, Mexico, with all other wild Zea species outside of this clade.

Much of what is known about the origins of domestication in Cucurbita comes from a combination of archaeological findings (e.g. Piperno \& Pearsall, 1998; Smith, 2006), studies of 
the genetic diversity within individual lineages in the genus (e.g. Decker-Walters et al., 2002; Ferriol et al., 2003; Paris et al., 2003; Andres, 2006; Heikal et al., 2008, Gong et al., 2012), and extensive observations of wild and cultivated Cucurbita taxa in their native ranges throughout North, Central, and South America (e.g. Nee, 1990). Some longstanding ideas about squash and pumpkin domestication therefore represent hypotheses that have not been supported with genetic data. Sanjur et al., (2002) hypothesized that the ancestor of C. pepo ssp. pepo is a close relative of the wild $C$. pepo ssp. fraterna, but no phylogeny has resolved the $C$. pepo clade to support this suggestion (e.g. Sanjur et al., 2002; Zheng et al., 2013; Kistler et al., 2015). Nee (1990) proposed northern Colombia as the likely site of origin of domestication for C. moschata, but no published phylogeny has included sufficient samples of this taxon to find a geographic center of phylogenetic diversity that allows for further investigation of this hypothesis with additional phylogeographic analyses.

Molecular phylogenetic studies of Cucurbita support the proposed ancestry of two of the six crops: $C$. maxima ssp. maxima (giant pumpkin, hubbard squash, kabocha squash) and $C$. argyrosperma ssp. argyrosperma (cushaw pumpkin, Japanese pie pumpkin) (Sanjur et al., 2002; Zheng et al., 2013; Kistler et al., 2015). However, the crop and breeding communities continue to rely on putative relationships such as those described above, and phylogenetic studies have thus far been unable to offer alternative hypotheses for the wild ancestors of four of the crop lineages (Sanjur et al., 2002; Zheng et al., 2013; Kistler et al., 2015). Although it is possible that the wild ancestors of crops with unclear ancestry are extinct, previous studies have also been limited by sparse taxonomic, geographic, and genetic sampling. Furthermore, the very recent and rapid diversification of the wild species and potential hybridization among Cucurbita species (Bemis \& Nelson, 1963) may impede phylogenetic inference using slow-evolving and maternally inherited chloroplast DNA sequence data.

Here we improve upon previous phylogenetic knowledge of Cucurbita through increased taxonomic, geographic, and genetic sampling. We present a phylogenetic reconstruction of all cultivated squashes, pumpkins, and gourds and 13 of the 14 crop wild relatives based on multiple, unlinked nuclear loci that provides the first support for close relationships between wild species and two of the six crop taxa. Through our study, we hope to enhance Cucurbita as a study system for investigating adaptive response to selection under domestication. 


\section{Materials and methods}

\subsection{Plant material and DNA extraction}

When species divergences are recent (resulting in incomplete lineage sorting), sampling more individuals per species leads to the reconstruction of a more accurate species tree (Maddison \& Knowles, 2006). Our analysis is the first reconstruction of Cucurbita phylogeny to include multiple individuals of 19 taxa, with 92 individuals from 19 of the 20 species, subspecies, and wild varieties of Cucurbita (all taxon names following Nesom, 2011). However, we were unable obtain material from $C$. radicans, a xerophytic species narrowly-distributed in western Mexico. Two outgroup species, Citrullus lanatus and Cucumis sativus, were selected based on phylogenetic results for Cucurbitaceae (Schaefer et al., 2011) (Supplementary Table 1). Leaf samples for DNA extraction were obtained from seedlings grown at the University of Florida, Gainesville, FL, from seeds obtained from the USDA or from herbarium specimens (Supplementary Table 1). DNA was extracted from fresh or dried leaf tissue using a modified $2 \mathrm{X}$ CTAB method (Doyle \& Doyle, 1987) yielding 50-120 ng/ $\mu$ l of DNA per sample. Modifications to the Doyle \& Doyle (1987) protocol include a second addition of chloroformisoamyl alcohol to the aqueous phase immediately following the first addition, and precipitation of DNA at $-20^{\circ} \mathrm{C}$ instead of room temperature. We used a precipitation time of thirty-minutes for fresh tissue and overnight for dried tissue.

\subsection{Selection of nuclear loci}

To improve the resolution of relationships within and among closely related taxa (following e.g. Parks et al., 2009; Steane et al., 2011), we sampled loci that are unlinked and more variable than those used in previous analyses of Cucurbita phylogeny (Sanjur et al., 2002; Zheng et al., 2013; Kistler et al., 2015). We identified 85 putatively single-copy, highly variable nuclear loci from a set of four reference genomes and transcriptomes (watermelon (Citrullus lanatus), cucumber (Cucumis sativus), melon (Cucumis melon), and pumpkin (Cucurbita pepo ssp. pepo; icugi.org), hereafter "cucurbit references") using a custom pipeline (Supplementary Fig. 1). Our pipeline selected intron sequences (400-700 bp) flanked by conserved exons with no highly similar sequence(s) likely to correspond to a paralog present in the same genome or transcriptome. Sequence similarity among putative genes in the four references was determined by BLAST with an e-value cutoff of 1.0e-5.

\subsection{Microfluidic PCR amplification and Illumina sequencing}


To amplify the 85 potentially phylogenetically informative loci, we used primer3 (Untergasser et al., 2012) in Geneious ver. 7.1 .9 (http://www.geneious.com, Kearse et al., 2012) to design primers with uniform $60^{\circ} \mathrm{C}$ annealing temperatures and no homopolymers of length greater than three, as recommended for the Fluidigm Access Array ${ }^{\mathrm{TM}}$ System (Fluidigm, San Francisco, CA, USA). We used alignments of the four cucurbit references to identify exon regions conserved across all cucurbit references and designed primers from C. pepo ssp. pepo exon sequences in these regions to amplify intron sequences (Supplementary Table 2).

In addition to the target-specific primer sequences identified, two conserved sequences (CS1 and CS2, Access Array ${ }^{\mathrm{TM}}$ System for Illumina Sequencing Systems User Guide) were added to the 5' end of both the forward and reverse primers to provide an annealing site for a second pair of custom-designed primers composed of the complementary CS sequence, Illumina adapters, and a sample-specific forward and reverse barcode to allow for all samples to be multiplexed in a fraction of a sequencing run.

Each primer set was validated prior to microfluidic PCR amplification to ensure success under the specific conditions on the Fluidigm Access Array ${ }^{\mathrm{TM}}$ (Uribe-Convers et al., 2016). We performed primer validation reactions on one of the species used for primer design, C. pepo, including both fresh and herbarium-derived samples, and on $C$. foetidissima, which is thought to be among the most phylogenetically distant species from C. pepo, based on previous phylogenetic studies (Zheng et al., 2013). We performed primer validation for each primer set in $10-\mu \mathrm{L}$ reactions following the Access Array ${ }^{\mathrm{TM}}$ System for Illumina Sequencing Systems User Guide. Reactions were as follows: $1 \mu \mathrm{L}$ of 10X FastStart High Fidelity Reaction Buffer without $\mathrm{MgCl}_{2}$ (Roche Diagnostic Corp., Indianapolis, Indiana, USA), $1.8 \mu \mathrm{L}$ of $25 \mathrm{mM} \mathrm{MgCl}$ (Roche), $0.5 \mu \mathrm{L}$ DMSO (Roche), $0.2 \mu \mathrm{L}$ 10mM PCR Grade Nucleotide Mix (Roche), $0.1 \mu \mathrm{L}$ of $5 \mathrm{U} / \mu \mathrm{L}$ FastStart High Fidelity Enzyme Blend (Roche), $0.5 \mu \mathrm{L}$ of $20 \mathrm{X}$ Access Array ${ }^{\mathrm{TM}}$ Loading Reagent (Fluidigm), $2 \mu \mathrm{L}$ of $2 \mu \mathrm{M}$ barcoded primers, $2 \mu \mathrm{L}$ of $50 \mathrm{nM}$ target-specific primers, $0.5 \mu \mathrm{L}$ of 25-50 ng/ $\mu \mathrm{L}$ genomic DNA, and 1.4 $\mu \mathrm{L}$ of PCR Certified Water. Resulting amplicons from successful primer validation reactions were analyzed using a Bioanalyzer High-Sensitivity Chip (Agilent Technologies, Santa Clara, California, USA), and the 48 primer pairs that produced a single amplicon of the expected size and that had no primer dimers were selected (Supplementary Table 2) for microfluidic PCR. 
Access Array ${ }^{\mathrm{TM}}$ System (Fluidigm) Microfluidic PCR, Illumina MiSeq sequencing, and quality-control steps were performed at the University of Idaho Institute for Bioinformatics and Evolutionary Studies Genomics Resources Core Facility. Microfluidic PCR was performed in an Access Array ${ }^{\mathrm{TM}}$ System (Fluidigm) using two 48.48 Access Array ${ }^{\mathrm{TM}}$ Integrated Fluidic Circuits (Fluidigm) following the manufacturer's protocols. On this array, 48 samples were simultaneously amplified using the 48 unique primer pairs described above. The resulting 2,304 unique PCR amplicons were harvested and pooled by individual in equal volumes and sequenced on $1 / 10^{\text {th }}$ of a run of an Illumina MiSeq using 300-bp paired-end reads.

\subsection{Assembly of sequencing reads into targeted nuclear loci}

Demultiplexing and assembly of Illumina sequencing reads followed Uribe-Convers $e t$ al. (2016). Briefly, Illumina sequencing reads were demultiplexed with the python preprocessing application dbcAmplicons (https://github.com/msettles/dbcAmplicons) by individual using the individual-specific dual barcode combinations and by locus using the target-specific primers. To address heterozygosity of nuclear loci, we performed two assemblies of Illumina reads into representative sequences for each of the 48 amplicons using the reduce_amplicons R script (https://github.com/msettles/dbcAmplicons/blob/master/scripts/R/ reduce_amplicons.R) described in Uribe-Convers et al. (2016). In cases where the target locus was longer than the paired-end read length, the two reads were concatenated into a single sequence prior to assembly with reduce_amplicons. One assembly used the "-p ambiguity" option to generate consensus sequences with IUPAC ambiguity codes, and the second assembly used the "-p occurrence" option to generate allelic occurrences for every individual at every locus. Briefly, "-p ambiguity" calls an ambiguity code for any site represented by more than one base when each variant is present in at least 5 reads and 5\% of the total of reads. The "-p occurrence" option assembles reads into two alleles at heterozygous loci by reducing reads to counts of identical reads if the count represents at least $5 \%$ of the total of reads and contains at least 5 reads. This method of assembly recovers true alleles if the following assumptions are met: sequencing errors are mostly random, and reads containing errors are present at much lower frequencies than real biological variation (Uribe-Convers et al., 2016). These two methods of assembly resulted in two data matrices for downstream analysis: 1) consensus sequences with IUPAC ambiguity codes (“ambiguity data set"), and 2) consensus sequences with two alleles per individual for any 
215

216

217

218

219

220

221

222

223

224

225

226

227

228

229

230

231

232

233

234

235

236

237

238

239

240

241

242

243

244

245

individual heterozygous at a locus ("allelic data set") such that each heterozygous individual was represented by two tips in gene trees.

\subsection{Sequence alignment and phylogenetic analyses}

Each locus was aligned with MUSCLE v 3.8.31 (Edgar, 2004) using default settings; alignments were visually inspected and edited in Geneious ver. 7.1.9 (http://www.geneious.com, Kearse et al., 2012). Alignments with data for fewer than 20 individuals were not included in the analyses, resulting in 42 alignments for both the ambiguity and allelic data sets. Two alignments were inferred to include paralogous loci based on the occurrence of more than two alleles per individual and preliminary maximum likelihood (ML) phylogeny reconstruction of each locus using RAxML v 8.2.3 (Stamatakis, 2014) and 1,000 bootstrap replicates under the GTRCAT model. Paralogy was inferred using gene phylogenies reconstructed as described above -- if two major clades were resolved that each contained a set of sequences that represented all or most sampled taxa then this was considered to represent paralogy. The paralogous loci were separated into four putative loci based on the major clades described above, resulting in data sets of 44 loci with a total aligned length of $20.3 \mathrm{~kb}$. Observed heterozygosity was calculated as the proportion of individuals with two alleles at a locus, averaged across 44 loci.

To compare alternative strategies for phylogenetic analyses of a multi-locus nuclear data set, we performed a concatenated analysis using ML ("CA-ML") of the ambiguity data set and species tree estimation using the gene trees inferred from the ambiguity and allelic data sets.

Prior to concatenation and species tree estimation, we conducted ML analysis of each locus using RAxML as described above for both the ambiguity and allelic alignments. We assessed taxon-level congruence of the resulting gene trees (with nodes with less than 50\% bootstrap support ("BS") collapsed) by visual inspection of each topology, rather than standard congruence tests, to avoid erroneous detection of incongruence due to missing data (Leigh et al., 2011).

Two likely sources of observed gene tree incongruence in our dataset are error in gene trees reconstructed from short loci and incomplete lineage sorting. We proceeded with CA-ML analysis despite gene tree incongruence because concatenation methods are robust to short loci but cannot account for incomplete lineage sorting. Thus comparison of CA-ML and species tree estimation results may aid in distinguishing incongruence due to gene tree error from that due to incomplete lineage sorting. Because there is no straightforward way to concatenate multiple alleles across alignments in the absence of a chromosomal linkage map (e.g. Edwards et al., 
2008), we did not analyze the allelic data set using the concatenated approach. ML analysis of the concatenated ambiguity data set was conducted using the hybrid MPI/Pthreads version of RAxML v 8.2.3 (Stamatakis, 2014) with 1,000 bootstrap replicates under the GTRCAT model. The GTRCAT model was selected using JModelTest2 (Darriba et al., 2012; Guindon and Gascuel 2003) and the CAT approximation of rate heterogeneity was used to accelerate computation (Stamatakis 2006).

We used a coalescent-based species tree approach as implemented in ASTRAL v 4.7.4 (Mirarab \& Warnow, 2015) to explore the effects of incongruence among gene trees on the species topology. ASTRAL is statistically consistent under the multi-species coalescent model and estimates a species tree given a set of unrooted gene trees (Mirarab \& Warnow, 2015). We present two results of ASTRAL species tree estimation: one from the allelic data set ("Sp-TRalleles") and one from the ambiguity data set ("Sp-TR-amb"). Each species tree was estimated from a set of 44 ML Majority-Rule-Consensus gene trees to reduce the effect of erroneous signals that may be present in poorly supported branches of best ML trees. For the allelic data set, we used a multi-individual mapping file (ASTRAL -a option) to map alleles to individuals in the case of heterozygotes as there is currently no feasible way to estimate a species tree from gene trees with multiple alleles per individual without mapping alleles to individuals. We performed multi-locus bootstrapping with 1,000 replicates for both trees.

\subsection{Ancestral state reconstruction}

We examined the evolution of mesophytic and xerophytic habits using a topology we manually constructed to represent species-level relationships all of which were resolved congruently in both the CA-ML and species trees. We used two outgroup taxa, Peponopsis adhaerens and Polyclathra cucumerina, placed based on the phylogeny of the entire family Cucurbitaceae ( Schaefer et al. 2009) to polarize the reconstruction. To create a bifurcating tree for ancestral character state reconstruction, we collapsed xerophytic species into two terminals (Xerophytes 1 and Xerophytes 2) that represent the two xerophytic clades of non-monophyletic species resolved in the species trees and CA-ML tree. Branch lengths for this tree were optimized in RAxML v 8.2.3 (Stamatakis, 2014) using an alignment of GenBank sequence data of four chloroplast loci with one representative for each terminal.

Habit (xerophytic or mesophytic) was scored from the literature (Schaefer \& Renner, 2011). We conducted ML reconstructions using the ACE (ancestral character estimations) 
277 function of the ape R package (Paradis et al.,, 2004; R Development Core Team, 2010). We

278 tested two alternative models, ER (equal rates; assuming equal transition rates between the

279 character states) and ARD (all-rates-different; transitions between the character states allowed to

280 vary freely). The ARD model had a higher log likelihood value of -4.54 compared with -4.61 .

281 However, a chi square test of the difference in log likelihood between the two models yielded a

282 p-value of 0.7 . We therefore did not accept the more heavily parameterized ARD model, and

283 instead chose the single-parameter ER model.

284

285

\section{Results}

286

287

288

289

290

291

292

293

294

295

296

297

298

299

300

301

302

303

304

305

306

\subsection{Sequence data}

Success of microfluidic PCR amplification was correlated with phylogenetic distance of a taxon to Cucurbita pepo ssp. pepo, from which the PCR primers were designed (Fig. 2). We did not observe a correlation between primer length and amplification success (Supplementary Fig. 2), and although we did observe a lower proportion of amplification success for samples derived from herbarium specimens (Supplementary Fig. 2), our sample set included four herbarium samples and ninety-four fresh leaf samples, so this comparison may be biased. The variable amplification success across taxa resulted in an initial data matrix with $42 \%$ missing data and $81 \%$ taxon coverage density (Fig. 2). However, substantially more missing data have been shown to be non-problematic in simulation and empirical studies (e.g. Driskell et al., 2004; Philippe et al., 2004; Wiens \& Moen, 2008; Wiens et al., 2010). In fact, including taxa with highly incomplete, non-random character sampling in phylogenetic analyses has been shown to dramatically improve results in some cases (Wiens 2006). Furthermore, some species trees methods, including ASTRAL, are robust to issues that arise because of non-random missing data when concatenation is used (Zhengxiang Xi et al. 2015). Nonetheless, to be cautious, we removed samples that occupied less than four gene alignments yielding a final data matrix of 94 samples with only $24 \%$ missing data. The numbers of aligned bases, including gaps, for 44 loci totaled $20.3 \mathrm{~kb} ; 19.9 \mathrm{~kb}$ nucleotide positions were variable. Heterozygosity varied among species between $\sim 7 \%$ in C. lundelliana and C. palmata to $\sim 43 \%$ in C. foetidissima, and observed heterozygosity was $22 \%$ overall.

3.2 Phylogeny of Cucurbita based on CA-ML and species tree methods 
The phylogeny of Cucurbita species provides strong support (BS 100\%) for the monophyly of the mesophytic species, including the domesticated figleaf gourd, $C$. ficifolia. The xerophytic species form a grade with $C$. digitata $+C$. cordata sister to the rest of $C u c u r b i t a$, and a clade formed by accessions of $C$. foetidissima and $C$. pedatifolia (neither of which is monophyletic) sister to all mesophytic species (Fig. 3). An accession of the xerophytic $C$. palmata is a member of each of these xerophytic clades.

The clade of mesophytic species includes the six Cucurbita crop lineages and their close relatives (Fig. 3). We recovered C. pepo (domesticated pumpkin, domesticated ornamental gourd, and their close wild relatives) sister to $C$. okeechobeensis $+C$. lundelliana. Together these three species are sister to the $C$. moschata (butternut squash) $+C$. argyrosperma (domesticated cushaw pumpkin and its close wild relative) clade. We resolved the species pair of C. maxima (giant pumpkin and its close wild relative) + C. ecuadorensis as sister to the rest of the mesophytic species.

For considerations of within-species resolution we will refer to the CA-ML tree, although we note that the concatenation method used can increase phylogenetic resolution despite incongruent within-species relationships among gene trees (cite). We define percent resolution within a clade as the number of nodes with $>50 \%$ BS divided by the number of possible bifurcations (two less than the number of tips). Cucurbita maxima is $42 \%$ resolved in the CAML tree (Fig. 3) and is the only species in which the cultivated and wild accessions form separate clades, with $100 \%$ and $92 \%$ BS, respectively. We did not observe a geographic association within the clade of cultivated accessions of $C$. maxima ssp. maxima.

Cucurbita argyrosperma is $31 \%$ resolved in the CA-ML tree (Fig. 3). In contrast to the pattern in C. maxima, the wild and cultivated accessions of $C$. argyrosperma do not form separate clades. Three of the five subclades recovered $(\mathrm{BS}>50 \%)$ include both wild and cultivated accessions. We included wild and cultivated accessions of $C$. argyrosperma from throughout both the native range and the range of cultivation in northwestern Mexico, eastern Mexico, southwestern Mexico, western Mexico, Central America, and the United States and found no geographic pattern associated with phylogenetic resolution within C. argyrosperma. The $C$. moschata clade is the best-resolved species clade in our phylogeny (71\% resolved in the CA-ML tree) (Fig. 3). We included accessions of $C$. moschata from throughout its range 
of cultivation in Mexico, Central America, South America, and the United States and found no clear geographic pattern to the relationships.

Cucurbita pepo is $48 \%$ resolved in the CA-ML tree (Fig. 3). We did not find internal support (i.e., BS > 50\%) for the monophyly of either of the two wild varieties of $C$. pepo ssp. ovifera, and the resolution among accessions of $C$. pepo ssp. ovifera was not correlated with geographic origin or taxonomy. The CA-ML tree resolves accessions of cultivated C. pepo ssp. ovifera in a clade with the three wild $C$. pepo taxa. The most widely cultivated pumpkin and squash, $C$. pepo ssp. pepo, forms a clade $(\mathrm{BS}=91 \%)$ sister to the rest of wild and cultivated $C$. pepo and thus is not sister to any wild accessions. Cucurbita pepo ssp. fraterna (wild) forms a clade (BS $=100 \%$ ) within the $C$. pepo minus $C$. pepo ssp. pepo (crop) clade.

Our phylogeny does not resolve accessions of $C$. okeechobeensis as a clade, and accessions of $C$. lundelliana form a clade in the Sp-TR-amb tree $(\mathrm{BS}=89 \%)$, but not in the CAML tree. There is lower support for relationships within the C. okeechobeensis $+C$. lundelliana clade in the CA-ML tree (Fig. 3) than in the Sp-TR-amb (Supplementary Fig. 3).

\subsection{Ancestral character state reconstruction}

The maximum likelihood reconstruction under the ER model showed that the xerophytic habit is the more likely character state for the ancestor of Cucurbita (ancestral state xerophytic: likelihood value $=59 \%$, ancestral state mesophytic $=41 \%)$.

\subsection{Differences in topology and support among the gene trees, CA-ML tree, and species trees}

The branching order of species we recovered here is congruent between both species trees and the CA-ML tree (Fig. 5). Bootstrap support for between and among species relationships is similar between the CA-ML tree and Sp-TR-amb tree (Fig. 5) and lower for some nodes in the Sp-TR-alleles tree, with two exceptions: 1) C. pepo sister to $C$. lundelliana $+C$. okeechobeensis has 100\% BS in the CA-ML tree compared with $72 \%$ in the Sp-TR-amb tree and $82 \%$ in the Sp-TR-alleles tree, and 2) the placement of the second-branching clade of xerophytic species sister to all mesophytic species has $75 \%$ BS in the CA-ML tree compared with $100 \%$ in the Sp-TR-amb tree and 97\% in the Sp-TR-alleles tree. The CA-ML tree has greatest withinspecies resolution and the $\mathrm{Sp}$-TR-alleles tree has the least within-species resolution. For example, C. pepo is $48 \%$ resolved in the CA-ML tree (Table 1), 36\% resolved in the Sp-TR-amb tree, and 16\% resolved in the Sp-TR-alleles tree. All species exhibit within-species incongruence to varying degrees between the CA-ML tree and the Sp-TR-amb tree (Fig. 5), and the low 
within-species resolution in the species trees is likely due in part to the use of majority-rule consensus gene trees to estimate these trees.

All gene trees (reconstructed from both ambiguity and allele sequences) had lower resolution than the CA-ML or species trees. The 44 ambiguity gene trees had an average of 80 tips and 29 bifurcations when branch lengths $<1$ e-5 were collapsed to reduce forced bifurcations. Out of the 44 ambiguity gene trees, six gene trees do not resolve most species as clades (with BS > 50\%) and thus do not support any species-level topology, 15 gene trees resolve a species-level topology congruent with the CA-ML tree and the species trees, and the remaining 23 gene trees support (BS > 50\%) alternative topologies (Supplementary Figs. 5-48). Gene tree incongruence with the CA-ML and species tree topologies is due to the variable position of $C$. ficifolia in ten of the gene trees and $C$. pepo in eight gene trees. The cause of incongruence in the remaining five gene trees varied. The 44 allele gene trees (Supplementary Figs. 49-92) were generally less resolved than the ambiguity gene trees, but showed a similar pattern of incongruence.

\section{Discussion}

\subsection{New Cucurbita species topology}

The species-level topology presented here (Fig. 3) includes two major clades of mesophytic species: five-species clade from North and Central America and a two-species clade from South America. The branching order within the five-species clade differs from that in previous studies (Fig. 4b,c) (Sanjur et al., 2002; Zheng et al., 2013; Kistler et al., 2015) and Zheng et al. (2013) did not recover these two clades (Fig. 4d). Only two relationships among the seven species in the mesophytic clades are consistent across all molecular phylogenetic studies conducted to date: C. maxima as sister to C. ecuadorensis, and C. lundelliana/C. okeechobeensis, The lack of reciprocal monophyly of $C$. lundelliana and $C$. okeechobeensis in our trees may be due to hybridization between the cross-compatible Mexican taxa, C. okeechobeensis ssp. martinezii and $C$. lundelliana (Whitaker \& Bemis, 1964). We also note however that $C$. okeechobeensis had the highest within-species proportion of missing data (65\%), and $C$. lundelliana had among the lowest proportion of within-species variable sites $(22 \%)$ and the characteristics of our data for these taxa could affect this result. The position of $C$. pepo (including the most widely cultivated Cucurbita crops) differs in each study conducted to date 
(Sanjur et al., 2002; Zheng et al., 2013; Kistler et al., 2015) and varies among our gene trees (Supplementary Figs. 5-92). Other studies resolved C. ficifolia, a mesophytic crop species that may live longer than a year without enlarged storage roots (Nee, 1990), as part of the grade of xerophytic species (Sanjur et al., 2002; Zheng et al., 2013; Kistler et al., 2015), in contrast to our study's placement of $C$. ficifolia as sister to the rest of the mesophytic species (Fig. 3, Supplementary Figs. 3,4).

The xerophytic species have not been evenly sampled in previous phylogenetic studies of Cucurbita, so we cannot directly compare the relationships among these species found here with previous analyses. In our trees, three morphologically and geographically distinct xerophytic species (Bemis \& Whitaker, 1969) are each reconstructed as non-monophyletic (C. foetidissima: paraphyletic, $C$. pedatifolia and $C$. palmata: polyphyletic). Although our sampling of these species is limited (Table 1), our results suggest the possibility of hybridization among xerophytic species. The three non-monophyletic xerophytic species are interfertile $(C$. pedatifolia and $C$. foetidissima, C. foetidissima and C. palmata), and where these species are sympatric they are known to hybridize (Bemis \& Whitaker 1969). The samples included here were not from the same geographic region (Supplementary Table 1), but past hybridization is a possibility as Cucurbita fruits can disperse long distances (Schaefer et al., 2009) and historical distributions of wild Cucurbita species were likely broader than they are currently (Kistler et al., 2015). Nonmonophyly of xerophytic species could also be due to lower variation in phylogenetic loci for xerophytic species compared with mesophytic annual Cucurbita species. Xerophytic Cucurbita are perennial species (Bemis \& Whitaker, 1969) and thus may have a slower rate of molecular evolution than the annual species included in this study (Andreasen \& Baldwin, 2001).

Phylogenetic studies of Cucurbita, including our results, have been based on DNA sequence data from one of three plant genomes (Sanjur et al., 2002: mitochondria; Zheng et al., 2013 and Kistler et al., 2015: chloroplast; our study: nuclear). A lack of congruence among phylogenetic trees across these three genomes may be due to reticulate evolution and/or a lack of phylogenetically informative characters in one or more of the trees (Knowles et al., 2011). Our phylogeny and that using whole plastomes (Kistler et al., 2015) were reconstructed from many variable DNA characters, but despite its large number of characters, the plastome is inherited as a linked unit and therefore must be regarded as a single locus (Doyle et al., 1990; Sun et al., 2016). 
Incongruence between our nuclear and the plastome phylogeny and among our gene trees

431

432

433 is unsurprising as incongruence among gene trees is expected in closely related species (e.g. Maddison, 1997; Degnan \& Rosenberg, 2009; Knowles, 2009), particularly groups suspected of hybridization and/or incomplete lineage sorting (Maureira-Butler et al., 2008; Gerard et al., 2011; Blanco-Pastor et al., 2012). Some gene trees reconstructed in this study (Supplementary Figs. 5-92) resolve topologies congruent with Kistler et al. (2015) (four gene trees), Zheng et al. (2013) (four gene trees), and Sanjur et al. (2002) (four gene trees) in part due to the variable placement of $C$. pepo and of $C$. ficifolia. The variable position of these species among gene trees suggests possible ancient hybridization or incomplete lineage sorting. Although we do not see clear evidence of widespread hybridization in the incongruence among alternative topologies or gene trees, the possibility of hybridization and hybrid origins in Cucurbita should be further studied with methods that model reticulate evolution (Shizhong Xu, 2000; Linder and Rieseberg 2004).

Species tree estimation is expected to be consistent under incomplete lineage sorting (Mirarab \& Warnow, 2015), therefore the higher BS value for the stem node of the mesophytic clade in the species trees (100\%) than in the CA-ML tree (75\%) (Fig. 5) supports incomplete lineage sorting as a probable cause of the incongruent position of the first-branching mesophytic species $C$. ficifolia among gene trees. In contrast, the lower BS value for the stem node of $C$. pepo in the Sp-TR-amb (73\%) than in the CA-ML tree (100\%) (Fig. 5) suggests the variable position of $C$. pepo may be due to weak phylogenetic signal associated with the low number of variable sites per gene (Patel et al., 2013; Smith et al., 2015) resulting in incongruence among gene trees due to error.

Whereas coalescent methods for species tree estimation assume that all gene trees used for the species tree estimation are correct and that any incongruence among the gene trees is due to incomplete lineage sorting, concatenation of loci overcomes the problem of short genes that may yield high-error gene trees by combining them into one longer locus with many variable sites (e.g. Gadagkar et al., 2005). This increase in variable sites is often needed to resolve relationships among closely related species (e.g. Edwards et al., 2008; Parks et al., 2009; Crowl et al., 2015; Uribe-Convers et al., 2016), and the Cucurbita CA-ML tree (Fig. 3) has high treewide support compared with the species trees (Supplementary Figs. 3, 4).

\subsection{Evolution of mesophytic habit in Cucurbita species}


Ancestral character-state reconstruction using the species-level topology (Fig. 3, Supplementary Figs. 3,4) support a xerophytic ancestor of Cucurbita and a single loss of the xerophytic habit during the evolution of Cucurbita species (Fig. 6). This finding differs from the hypothesis of Zheng et al., (2013) of multiple derivations of the mesophytic habit within Cucurbita and/or a mesophytic ancestor in part due to the position of $C$. ficifolia in our phylogeny. Cucurbita ficifolia is a crop that lacks drought-resistance and enlarged storage roots but has been resolved within the xerophytic grade in previous phylogenetic trees (Sanjur et al., 2002; Zheng et al., 2013; Kistler et al., 2015). Although our results point to a more parsimonious trait evolution than do previous studies, a set of the 44 gene trees resolved $C$. ficifolia as sister to xerophytic species as described above.

The placement of the South American C. maxima + C. ecuadorensis clade as sister to the rest of the North American mesophytic species suggests a period of diversification within the ancestral range of Cucurbita, as well as by dispersal into new areas. This diversification and dispersal appears tofollow the evolution of the mesophytic habit perhaps as mesophytic forms occupied new ecological niches in wetter climates south of the center of diversity of Cucurbita. The poor resolution of the backbone of the Cucurbita tree in individual gene trees points to rapid diversification following the evolution of the mesophytic habit. This hypothesis of recent and rapid radiation could explain in part why different Cucurbita phylogenies do not converge on a single topology of the mesophytic species. Biogeographic and diversification analyses of a Cucurbita phylogeny reconstructed with broader geographic sampling than we have included in this study are needed to address the above hypotheses.

\subsection{Phylogenetic resolution within clades of crops and their wild relatives}

We found variable patterns of resolution within each of five clades that include domesticates (domesticated $C$. ficifolia is excluded here due to insufficient sampling) to inform hypotheses for the number and magnitude of initial domestications for the Cucurbita crops. Accessions of C. pepo ssp. ovifera var. ovifera (ornamental gourd) and C. argyrosperma ssp. argyrosperma (cushaw pumpkin) included here both form multiple clusters that include both wild and domesticated accessions (three wild C. pepo taxa and C. argyrosperma ssp. sororia, respectively) (Fig. 3). This pattern is similar to that observed in crops found to have multiple centers of diversification, broad domestication bottlenecks, and/or introgression between wild 
491

492

493

494

495

496

497

498

499

500

501

502

503

504

505

506

507

508

509

510

511

512

513

514

515

516

517

518

519

520

521

and domesticated species in other crops (e.g. African rice: Li et al., 2011; olive: Diez et al., 2015; kabuli chickpea: Penmetsa et al., 2016).

These two crop-wild clades are each sister to a second crop clade: $C$. pepo ssp. ovifera/C. pepo ssp. fraterna (crop-wild) is sister to C. pepo ssp. pepo (crop), and C. argyrosperma (cropwild) is sister to C. moschata (crop) (Fig. 3). The possibility of a related domestication history for each of these two crop/crop-wild pairs may need to be considered. A shared domestication history between two Cucurbita crops has only been considered (though not supported by molecular studies: Decker, 1987; Decker, 1988) in C. pepo because C. argyrosperma and $C$. moschata, though interfertile, did not appear to hybridize when grown together (Merrick, 1990). In addition, the wide diversity of fruit types in C. moschata cultivated in South America led to hypotheses that South America is the more likely range of its wild ancestor (Nee, 1990; WesselBeaver, 2000). However, our phylogeny resolves separate South American and North American/Central American Cucurbita clades, and the membership of C. moschata in the North America/Central America clade (Fig. 3) makes it unlikely that the closest wild ancestor of $C$. moschata, if extinct or uncollected, would be found in South America. Furthermore, at least one study has now confirmed natural hybridization between C. argyrosperma and C. moschata (Wessel-Beaver, 2000).

In contrast to the similar pattern of relatedness within and between the four Cucurbita crops included in $C$. pepo and $C$. argyrosperma $+C$. moschata, the crop and wild accessions of C. maxima (giant pumpkin) form two sister clades and this crop-wild clade is not sister to another crop clade (Fig. 3). The resolution of $C$. maxima into separate wild and crop clades is similar to patterns seen in crops for which single domestications and low introgression between crop and wild taxa have been hypothesized (e.g. Einkorn wheat: Heun et al., 1997; maize: Matsuoka et al., 2002; soybean: Guo et al., 2010). The phylogenetic resolution and observed heterozygosity among accessions of cultivated $C$. maxima ssp. maxima included in our study are the lowest of all the Cucurbita crops, further supporting the hypothesis of a narrow domestication bottleneck and a single domestication and limited post-domestication diversification for C. maxima. The within-species resolution in our Cucurbita phylogeny provides an initial framework for domestication-genetics studies to test these and other hypotheses of Cucurbita domestication.

\section{Conclusions}


Advances in methods for phylogeny reconstruction and the expansion of expert-curated seed banks of crops and crop-wild-relatives have enabled rigorous investigations into the genetic origins of domesticated species. Ours is the first phylogenetic study to include multiple accessions of all known wild Cucurbita species and to use many, unlinked genetic loci to reconstruct relationships between these species and the six Cucurbita crop lineages. The novel relationships recovered provide new information about the evolution of Cucurbita and the patterns of diversity within Cucurbita crops and their wild relatives. We also demonstrate the need to study the evolution of closely related species using multiple, unlinked nuclear genes, as the relationships recovered in Cucurbita using these loci differ from those recovered using organellar loci.

The lack of close wild relatives identified in this study for C. moschata, $C$. ficifolia, and C. pepo ssp. pepo may be due in part to widespread extinction of wild Cucurbita, as proposed by Kistler et al. (2015) and to inadequate sampling of wild Cucurbita from regions of possible domestication. Future work to uncover the origins of these three Cucurbita crops must begin with an extensive effort to survey and collect wild Cucurbita from these geographic regions. The three Cucurbita crops for which we have recovered well-supported relationships to wild species, C. maxima ssp. maxima, C. argyrosperma ssp. sororia, and C. pepo ssp. ovifera var. ovifera, present ideal models in which to study the genetic and demographic processes of plant domestication.

\section{Acknowledgments}

We thank K. Perkins and G. Ferguson for kindly facilitating sampling of herbarium material for DNA sequencing from FLAS and ARIZ, respectively, and T. Fields, K. R. Reitsma, J. Preece, and S. Tennies for facilitating access to seed material for DNA sequencing from USDA ARS repositories S9, NC7, PARL, and NE9 respectively. We thank the International Cucurbit Genomics Initiative (ICuGI) for the publicly available sequences used for locus selection, D. Tank and S. Uribe-Convers for providing advice on use of the Fluidigm Access Array ${ }^{\mathrm{TM}}$ System for phylogenetics, M. Settles for help with sequence assembly, and A. Ulmer and C. Walsh for help with lab work. We thank two anonymous reviewers for their constructive comments that improved the quality of this manuscript. This work was supported by NSF grant 
DEB-1406960 (Doctoral Dissertation Improvement Grant to D.E.S., P.S.S., and H.R.K.); the American Society of Plant Taxonomists; and the Botanical Society of America.

\section{Figure legends}

Figure 1 Distribution map of wild species of Cucurbita with occurrences based on $~ 7000$ records from GBIF (www.gbif.org). Hypothesized origins of domestication for the six Cucurbita crop lineages are indicated by open circles. Colors correspond to tip colors in Figure 3: Cucurbita pepo ssp. ovifera var. ovifera: dark green; $C$. pepo ssp. pepo: light green; $C$. argyrosperma ssp. argyrosperma: blue; C. moschata: magenta; $C$. ficifolia: light blue; $C$. maxima ssp. andreana: orange.

Figure 2 Success of microfluidic PCR amplification of loci across taxa. Highlighted taxon $C$. реро ssp. реро was used for locus-selection and primer design. Black indicates that a locus was amplified for all individuals of the corresponding taxon, white indicates the locus was not successfully amplified for any individuals of the corresponding taxon. Tree illustrates relationships among these taxa as reconstructed in this study. Not all samples and loci presented in this heatmap of amplification success were ultimately included in the analyses presented in this paper.

Figure 3 Best maximum-likelihood tree reconstructed with RAxML using a matrix of concatenated ambiguity-coded gene sequences under the GTRCAT model. Support values are from 1,000 bootstrap replicates. BS values $<50 \%$ are not shown. Outgroup branch lengths are scaled to $1 / 10$ of actual length to accommodate viewing of ingroup.

Figure 4 Comparison of alternative branching patterns among seven mesophytic Cucurbita species resolved by four phylogenetic studies of Cucurbita. a. The topology found in this study; b. Sanjur et al. (2002); c. Kistler et al. (2015); d. Zheng et al. (2013). Mesophytic species Cucurbita ficifolia is excluded due its position outside of this clade in some previous studies. 
581

582

583

584

585

586

587

588

589

590

591

592

593

594

595

596

597

598

599

600

601

602

603

604

605

606

607

Figure 5. Comparison of the ML phylogeny inferred from the concatenated matrix and ASTRAL species tree estimated from ambiguity-coded gene trees, with branches not found in both trees highlighted in red. Nodes with $<50 \%$ BS are collapsed in both trees. Support values are shown in black for incongruent nodes and in red where BS values disagree between the two trees by more than ten points.

Figure 6 Ancestral character-state reconstruction of habit using maximum likelihood. Possible states are mesophytic habit (black) and xerophytic habit (gray). Relative likelihood probabilities for each character state are represented with a pie chart at nodes.

\section{References}

Andreasen K, Baldwin BG. 2001. Unequal Evolutionary Rates Between Annual and Perennial Lineages of Checker Mallows (Sidalcea, Malvaceae): Evidence from 18S-26S rDNA Internal and External Transcribed Spacers. Mol Biol Evol 18 (6): 936-944.

Andres TC., 2006. Origin, morphological variation, and uses of Cucurbita ficifolia, the mountain squash. Cucurbitaceae 2006, Asheville, North Carolina, USA: 326-332.

Atkinson RG, Cipriani G, Whittaker DJ, Gardner RC., 1997. The allopolyploid origin of kiwifruit, Actinidia deliciosa (Actinidiaceae). Plant Systematics and Evolution 205(1-2), 111-124.

Bayzid MS, Warnow T. 2013. Naive binning improves phylogenomic analyses. Bioinformatics 29(18), 2277-2284.

Bemis WP., Nelson JM. 1963. Interspecific Hybridization within the Genus Cucurbita I, Fruit Set, Seed and Embryo Development. Journal of Ariz. Acad. of Sci. 2(3): 104-107.

Bemis WP, Whitaker TW., 1969. The Xerophytic Cucurbita of Northwestern Mexico and Southwestern United States. Madro 20(2), 33-41.

Caicedo AL, Schaal BA. 2004. Population structure and phylogeography of Solanum pimpinellifolium inferred from a nuclear gene. Molecular Ecology 13(7), 1871-1882. 
608 609

610

611

612

613

614

615

616

617

618

619

620

621

622

623

624

625

626

627

628

629

630

Collins AG, Cartwright P, McFadden CS, Schierwater B. 2005. Phylogenetic context and basal metazoan model systems. Integrative and Comparative Biology 45(4), 585-594.

Crowl AA, Visger CJ, Mansion G, Hand R, Wu H-H, Kamari G, Phitos D, Cellinese N. 2015. Evolution and biogeography of the endemic Roucela complex (Campanulaceae: Campanula) in the Eastern Mediterranean. Ecology and Evolution 5(22), 5329-5343.

Darriba, D., Taboada GL, Doallo R, Posada D. 2012. jModelTest 2: more models, new heuristics and parallel computing. Nature Methods. 9,772.

Decker DS. 1988. Origin(s), evolution, and systematics of Cucurbita (Cucurbitaceae). Economic Botany 42(1), 4-15.

Decker DS, Wilson HD. 1987. Allozyme variation in the Cucurbita pepo complex - Cucurbitapepo var. ovifera vs Cucurbita texana. Systematic Botany 12(2), 263-273.

Decker-Walters D, Staub J, Chung S, Nakata E, Quemada H. 2002. Diversity in free-living Populations of Cucurbita pepo (Cucurbitaceae) as assessed by random amplified polymorphic DNA. Systematic Botany 27(1), 19-28.

Decker-Walters DS, Walters TW, Cowan CW, Smith BD. 1993. Isozymic characterization of wild populations of Cucurbita pepo. Journal of Ethnobiology 13: 55-72.

Degnan JH, Rosenberg NA. 2009. Gene tree discordance, phylogenetic inference and the multispecies coalescent. Trends Ecol Evol 24(6), 332-340.

Diez CM, Trujillo I, Martinez-Urdiroz N, Barranco D, Rallo L, Marfil P, Gaut BS. 2015. Olive domestication and diversification in the Mediterranean Basin. New Phytologist 206(1), 436-447.

Doebley JF, Iltis HH. 1980. Taxonomy of Zea (gramineae) A subgeneric classification with key to taxa. American Journal of Botany 67(6), 982-993. 
631

632

633

634

635

636

637

638

639

640

641

642

643

644

645

646

647

648

649

650

651

652

653

654

Doyle JJ, Doyle JL 1987. A rapid DNA isolation procedure for small quantities of fresh leaf tissue: Phytochemical Bulletin. 11-15.

Doyle JJ, Doyle JL, Brown AHD. 1990. A chloroplast-DNA phylogeny of the wild perennial relatives of soybean (Glycine subgenus Glycine) - congruence with morphological and crossing groups. Evolution 44(2), 371-389.

Driskell AC, Ane C, Burleigh JG, McMahon MM, O'Meara BC, Sanderson MJ. 2004. Prospects for building the tree of life from large sequence databases. Science 306(5699), 11721174.

Edgar RC. 2004. MUSCLE: multiple sequence alignment with high accuracy and high throughput. Nucleic Acids Research 32(5), 1792-1797.

Edwards CE, Lefkowitz D, Soltis DE, Soltis PS. 2008. Phylogeny of Conradina and related southeastern scrub mints (Lamiaceae) based on GapC gene sequences. International Journal of Plant Sciences 169(4), 579-594.

Felsenstein J. 1973. Maximum likelihood and minimum-steps methods for estimating evolutionary trees from data on discrete characters. Systematic Zoology 22(3), 240-249.

Ferriol M, Pico B, de Cordova PF, Nuez F. 2004. Molecular diversity of a germplasm collection of squash (Cucurbita moschata) determined by SRAP and AFLP markers. Crop Science 44(2), 653-664.

Gadagkar SR, Rosenberg MS, Kumar S. 2005. Inferring species phylogenies from multiple genes: Concatenated sequence tree versus consensus gene tree. Journal of Experimental Zoology Part B-Molecular and Developmental Evolution 304B(1), 64-74.

Gepts P. 1996. Origin and evolution of cultivated Phaseolus species. In: Pickersgill, B. \& Lock JM., eds. Advances in Legume Systematics, Part 8; Legumes of economic importance. London, UK: Kew publishing, 65-74. 
655 Gerard D, Gibbs HL, Kubatko L. 2011. Estimating hybridization in the presence of coalescence 656 using phylogenetic intraspecific sampling. Bmc Evolutionary Biology 11:291

657

658

659

660

661

662

663

664

665

666

667

668

669

670

671

672

673

674

675

676

677

678

Gong L, Paris HS, Nee MH, Stift G, Pachner M, Vollmann J, Lelley T. 2012. Genetic relationships and evolution in Cucurbita pepo (pumpkin, squash, gourd) as revealed by simple sequence repeat polymorphisms. Theoretical and Applied Genetics 124(5), 875891.

Guindon S, Gascuel O. 2003. A simple, fast, and accurate algorithm to estimate large phylogenies by maximum likelihood. Systematic Biology 52(5), 696-704.

Guo J, Wang Y, Song C, Zhou J, Qui L, Huang H, Wang Y. 2010. A single origin and moderate bottleneck during domestication of soybean (Glycine max), Implications from microsatellites and nucleotide sequences. Annals of Botany 106(3), 505-514.

Heikal AH, Abdel-Razzak HS, Hafez EE. 2008. Assessment of genetic relationships among and within Cucurbita species using RAPD and ISSR markers. Journal of Applied Sciences Research (5), 515-525.

Heled J, Drummond AJ. 2010. Bayesian Inference of Species Trees from Multilocus Data. Molecular Biology and Evolution 27(3), 570-580.

Heun M, SchaferPregl R, Klawan D, Castagna R, Accerbi M, Borghi B, Salamini F. 1997. Site of einkorn wheat domestication identified by DNA fingerprinting. Science 278(5341), 13121314.

Hoffman DL, Soltis DE, Muehlbauer FJ, Ladizinsky G. 1986. Isozyme polymorphism in Lens (Leguminosae). Systematic Botany 11(3), 392-402.

Huang X, Han B. 2012. A crop of maize variants. Nature Genetics 44(7), 734-735.

Igea J, Juste J, Castresana J. 2010. Novel intron markers to study the phylogeny of closely related mammalian species. Bmc Evolutionary Biology 10:369 
Jing R, Vershinin A, Grzebyta J, Shaw P, Smykal P, Marshall D, Ambrose MJ, Ellis THN, Flavell AJ. 2010. The genetic diversity and evolution of field pea (Pisum) studied by high throughput retrotransposon based insertion polymorphism (RBIP) marker analysis. Bmc Evolutionary Biology 10:44

Kearse M, Moir R, Wilson A, Stones-Havas S, Cheung M, Sturrock S, Buxton S, Cooper A, Markowitz S, Duran C, et al., 2012. Geneious Basic: An integrated and extendable desktop software platform for the organization and analysis of sequence data. Bioinformatics 28(12), 1647-1649.

Kellogg EA, Birchler JA. 1993. Linking phylogeny and genetics - Zea-mays as a tool for phylogenetic studies. Systematic Biology 42(4), 415-439.

Kistler L, Newsom LA, Ryan TM, Clarke AC, Smith BD, Perry GH. 2015. Gourds and squashes (Cucurbita spp.) adapted to megafaunal extinction and ecological anachronism through domestication. Proceedings of the National Academy of Sciences of the United States of America 112(49), 15107-15112.

Knowles LL, Klimov PB. 2011. Estimating phylogenetic relationships despite discordant gene trees across loci: the species tree of a diverse species group of feather mites (Acari: Proctophyllodidae). Parasitology 138(13), 1750-1759.

Knowles LLCFpdO. 2009. Estimating species trees: methods of phylogenetic analysis when there is incongruence across genes. Systematic Biology 58(5), 463-467.

Kubatko LS, Carstens BC, Knowles LL. 2009. STEM: species tree estimation using maximum likelihood for gene trees under coalescence. Bioinformatics 25(7), 971-973.

Leigh JW, Lapointe F-J, Lopez P, Bapteste E. 2011. Evaluating Phylogenetic Congruence in the Post-Genomic Era. Genome Biology and Evolution 3: 571-587.

Li ZM, Zheng XM, Ge S. 2011. Genetic diversity and domestication history of African rice (Oryza glaberrima) as inferred from multiple gene sequences. Theoretical and Applied Genetics 123(1), 21-31. 
705 706

Linder CR., Rieseberg LH. 2004. Reconstructing patterns of reticulate evolution in plants. Amer. Journal of Botany 91(10): 1700-8.

Liu L, Pearl DK. 2007. Species Trees from Gene Trees: Reconstructing Bayesian Posterior Distributions of a Species Phylogeny Using Estimated Gene Tree Distributions. Systematic Biology 56(3), 504-514.

Liu L, Yu L, Kubatko L, Pearl DK, Edwards SV. 2009. Coalescent methods for estimating phylogenetic trees. Molecular Phylogenetics and Evolution 53(1), 320-328.

Liu X-J, Li Y-J, Liang G-Y, Fang C, Liu D-C, Yang H, Zhao Y. 2010. Genetic diversity of some accessions in Cucurbita by SRAP markers. Sichuan Daxue Xuebao (Ziran Kexueban) 47(5), 1195-1200.

Luis Blanco-Pastor J, Vargas P, Pfeil BE. 2012. Coalescent Simulations Reveal Hybridization and Incomplete Lineage Sorting in Mediterranean Linaria. Plos One 7(6).

Maddison WP. 1997. Gene trees in species trees. Systematic Biology 46(3), 523-536.

Maddison WP, Knowles LL. 2006. Inferring phylogeny despite incomplete lineage sorting. Systematic Biology 55(1), 21-30.

Matsuoka Y, Vigouroux Y, Goodman MM, Sanchez GJ, Buckler E, Doebley J. 2002. A single domestication for maize shown by multilocus microsatellite genotyping. Proceedings of the National Academy of Sciences of the United States of America 99(9), 6080-6084.

Maureira-Butler IJ, Pfeil BE, Muangprom A, Osborn TC, Doyle JJ. 2008. The reticulate history of Medicago (Fabaceae). Systematic Biology 57(3), 466-482.

Merrick L. C. 1990. Systematics and evolution of a domesticated squash, Cucurbita argyrosperma, and its wild and weedy relatives. In: D. M. Bates, R. W. Robinson, and C. Jeffrey, eds. Biology and utilization of the Cucurbitaceae. New York, USA: Cornell University Press, 77-95. 
Mayer MS, Soltis PS. 1994. Chloroplast DNA phylogeny of Lens (Leguminosae) - origin and diversity of the cultivated lentil. Theoretical and Applied Genetics 87(7), 773-781.

Meyer RS, Karol KG, Little DP, Nee MH, Litt A. 2012. Phylogeographic relationships among Asian eggplants and new perspectives on eggplant domestication. Molecular Phylogenetics and Evolution 63(3), 685-701.

Mirarab S, Warnow T. 2015. ASTRAL-II: coalescent-based species tree estimation with many hundreds of taxa and thousands of genes. Bioinformatics 31(12), 44-52.

Nee M. 1990. The domestication of Cucurbita (Cucurbitaceae). Economic Botany 44(3), 56-68.

Nesom GL 2011. New state records for Citrullus, Cucumis, and Cucurbita (Cucurbitaceae) outside of cultivation in the USA. Phytoneuron. 1-7.

Olsen KM, Purugganan MD. 2002. Molecular evidence on the origin and evolution of glutinous rice. Genetics 162(2), 941-950.

Olsen KM, Schaal BA. 1999. Evidence on the origin of cassava: Phylogeography of Manihot esculenta. Proceedings of the National Academy of Sciences of the United States of America 96(10), 5586-5591.

Paradis E, Claude J, Strimmer K. 2004. APE: Analyses of Phylogenetics and Evolution in R language. Bioinformatics 20(2), 289-290.

Paris H, Yonash N, Portnoy V, Mozees-Daube N, Tzuri G, Katzir N. 2003. Assessment of genetic relationships in Cucurbita pepo (Cucurbitaceae) using DNA markers. Theoretical and Applied Genetics 106(6), 971-978.

Parks M, Cronn R, Liston A. 2009. Increasing phylogenetic resolution at low taxonomic levels using massively parallel sequencing of chloroplast genomes. Bmc Biology 7:84.

Patel SK, R.T. Braun, E.L. 2013. Error in phylogenetic estimation for bushes in the tree of life: Phylogenet. Evol. Biol. 1:110. 
Penmetsa, VR., Carrasquilla-Garcia, N., Bergmann, E. M., Vance, L., Castro, B., Kassa, M. T., Sarma, B. K., Datta, S., Farmer, A. D., Baek, J.-M., Coyne, C. J., Varshney, R. K., von Wettberg, E. J. B.,Cook, D. R. 2016. Multiple post-domestication origins of kabuli chickpea through allelic variation in a diversification-associated transcription factor. New Phytol 211: 1440-1451.

Philippe H, Snell EA, Bapteste E, Lopez P, Holland PWH, Casane D. 2004. Phylogenomics of eukaryotes: Impact of missing data on large alignments. Molecular Biology and Evolution 21(9), 1740-1752.

Piperno DR, Pearsall DM 1998. The Origins of Agriculture in the Lowland Neotropics. San Diego: USA: Academic Press, 109-166.

Sanjur OI, Piperno DR, Andres TC, Wessel-Beaver L. 2002. Phylogenetic relationships among domesticated and wild species of Cucurbita (Cucurbitaceae) inferred from a mitochondrial gene: Implications for crop plant evolution and areas of origin. Proceedings of the National Academy of Sciences of the United States of America 99(1), 535-540.

Savage JA, Haines DF, Holbrook NM. 2015. The making of giant pumpkins: how selective breeding changed the phloem of Cucurbita maxima from source to sink. Plant Cell and Environment 38(8), 1543-1554.

Schaefer H, Heibl C, Renner SS. 2009. Gourds afloat: a dated phylogeny reveals an Asian origin of the gourd family (Cucurbitaceae) and numerous oversea dispersal events. Proceedings of the Royal Society B-Biological Sciences 276(1658), 843-851.

Schaefer H, Renner SS 2011. Cucurbitaceae. In: Kubitzki K ed. Flowering Plants. Eudicots Sapindales, Cucurbitales, Myrtaceae. New York, USA: Springer, 112-174.

Simmons MP, Gatesy J. 2015. Coalescence vs. concatenation: Sophisticated analyses vs. first principles applied to rooting the angiosperms. Molecular Phylogenetics and Evolution 91: 98-122. 
800

Smith BD. 1997. The Initial Domestication of Cucurbita pepo in the Americas 10,000 Years Ago. Science 276(5314), 932-934.

Smith SA, Moore MJ, Brown JW, Yang Y. 2015. Analysis of phylogenomic datasets reveals conflict, concordance, and gene duplications with examples from animals and plants. Bmc Evolutionary Biology 15:150.

Smýkal P, Kenicer G, Flavell AJ, Corander J, Kosterin O, Redden RJ, Ford R, Coyne CJ, Maxted N, Ambrose MJ, et al., 2011. Phylogeny, phylogeography and genetic diversity of the Pisum genus. Plant Genetic Resources 9(1), 4-18.

Stamatakis A. 2006. RAxML-VI-HPC: maximum likelihood-based phylogenetic analyses with thousands of taxa and mixed models. Bioinformatics 22(21), 2688-2690.

Stamatakis A. 2014. RAxML version 8: a tool for phylogenetic analysis and post-analysis of large phylogenies. Bioinformatics 30(9), 1312-1313.

Steane DA, Nicolle D, Sansaloni CP, Petroli CD, Carling J, Kilian A, Myburg AA, Grattapaglia D, Vaillancourt RE. 2011. Population genetic analysis and phylogeny reconstruction in Eucalyptus (Myrtaceae) using high-throughput, genome-wide genotyping. Molecular Phylogenetics and Evolution 59(1), 206-224.

Sun Y, Moore MJ, Zhang S, Soltis PS, Soltis DE, Zhao T, Meng A, Li X, Li J, Wang H. 2016. Phylogenomic and structural analyses of 18 complete plastomes across nearly all families of early-diverging eudicots, including an angiosperm-wide analysis of IR gene content evolution. Molecular Phylogenetics and Evolution 96: 93-101.

R Core Team 2014. R: A language and environment for statistical computing. $R$ Foundation for Statistical Computing. [WWW document] URL http://www.R-project.org/ [accessed 1 June 2016].

Untergasser A, Cutcutache I, Koressaar T, Ye J, Faircloth BC, Remm M, Rozen SG. 2012. Primer3--new capabilities and interfaces. Nucleic Acid Research 40(15), 115 
Uribe-Convers S, Settles ML, Tank DC. 2016. A Phylogenomic Approach Based on PCR Target Enrichment and High Throughput Sequencing: Resolving the Diversity within the South American Species of Bartsia L. (Orobanchaceae). Plos One 11(2).

811 Walters TW, Decker-Walters DS. 1993. Systematics of the endangered okeechobee gourd 812 (Cucurbita okeechobeensis Cucurbitaceae). Systematic Botany 18(2), 175-187.

813

814

815

816

817

818

819

820

821

822

823

824

825

826

827

828

829

830
Ward DB, Minno MC. Rediscovery of the Endangered Okeechobee Gourd (Cucurbita okeechobeensis) along the St. Johns River, Florida, Where Last Reported by William Bartram in 1774. Castanea 67(2), 201-206.

Warnow T. Concatenation Analyses in the Presence of Incomplete Lineage Sorting. 2015. PLOS Currents Tree of Life. Ed. 1 doi: 10.1371/currents.tol.8d41ac0f13d1abedf4c4a59f5d17b1f7.

Wessel-Beaver L. 2000. Cucurbita argyrosperma sets fruit in fields where C. moschata is only pollen source. Cucurbit Genetics Cooperative Report 23: 62-63.

Whitaker TW., Bemis WP. 1964. Evolution in the genus Cucurbita. Evolution 18: 553-559.

Wiens JJ. 2006. Missing data and the design of phylogenetic analyses. 2006. Journal of Biomedical Informatics 39(1), 34-42.

Wiens JJ, Kuczynski CA, Townsend T, Reeder TW, Mulcahy DG, Sites JW. 2010. Combining Phylogenomics and Fossils in Higher-Level Squamate Reptile Phylogeny: Molecular Data Change the Placement of Fossil Taxa. Systematic Biology 59(6), 674-688.

Wiens JJ, Moen DS. 2008. Missing data and the accuracy of Bayesian phylogenetics. Journal of Systematics and Evolution 46(3), 307-314.

Wiens JJ, Morrill MC. 2011. Missing Data in Phylogenetic Analysis: Reconciling Results from Simulations and Empirical Data. Systematic Biology 60(5), 719-731. 
831 Wilkes HG. 1977. Hybridization of maize and teosinte in Mexico and Guatemala and 832 improvement of maize. Economic Botany 31(3), 254-293.

833 Xu, SZ. 2000. Phylogenetic analysis under reticulate evolution. Mol Biol Evol 17(6):897-907.

834 Zheng Y-H, Alverson AJ, Wang Q-F, Palmer JD. 2013. Chloroplast phylogeny of Cucurbita:

835 Evolution of the domesticated and wild species. Journal of Systematics and

$836 \quad$ Evolution 51(3), 326-334.

837 Zhenxiang Xi, Liang Liu, Charles CD. 2015. The Impact of Missing Data on Species Tree $838 \quad$ Estimation. Mol Biol Evol 2016; 33 (3): 838-860.

839

840 


\begin{tabular}{|c|c|c|c|c|}
\hline Species & $\begin{array}{l}\text { No. } \\
\text { Individuals } \\
\text { sampled/tips }\end{array}$ & Bifurcations & $\begin{array}{l}\text { Percent } \\
\text { Resolution }\end{array}$ & $\begin{array}{l}\text { Example } \\
\text { crop types }\end{array}$ \\
\hline $\begin{array}{l}\text { Cucurbita pepo ssp. } \\
\text { pepo }^{\mathrm{c}} \text {, C. pepo ssp. } \\
\text { ovifera var. ovifera }^{\mathrm{c}} \text {, } \\
\text { C. pepo ssp. ovifera } \\
\text { var. texana }^{\mathrm{w}} \text {, C. pepo } \\
\text { ssp. ovifera var. } \\
\text { ozarkana }^{\mathrm{w}}, \text { C. pepo } \\
\text { ssp. fraterna }{ }^{\mathrm{w}}\end{array}$ & 27 & 12 & $48 \%$ & $\begin{array}{l}\text { jack-o- } \\
\text { lantern } \\
\text { pumpkin, } \\
\text { zucchini, } \\
\text { summer } \\
\text { squash, } \\
\text { spaghetti } \\
\text { squash; } \\
\text { acorn } \\
\text { squash, } \\
\text { ornamental } \\
\text { gourd }\end{array}$ \\
\hline $\begin{array}{l}\text { Cucurbita maxima } \\
\text { ssp. maxima }{ }^{\mathrm{c}}, C \text {. } \\
\text { maxima } \mathrm{ssp} . \\
\text { andreana }^{\mathrm{w}}\end{array}$ & 14 & 5 & $42 \%$ & $\begin{array}{l}\text { giant } \\
\text { pumpkin, } \\
\text { hubbard } \\
\text { squash, } \\
\text { kabocha } \\
\text { squash }\end{array}$ \\
\hline $\begin{array}{l}\text { Cucurbita } \\
\text { argyrosperma ssp. } \text { argyrosperma }^{\mathrm{c}}, C . \\
\text { argyrosperma } \mathrm{ssp} .^{\text {sororia }^{\mathrm{w}}}\end{array}$ & 15 & 4 & $31 \%$ & $\begin{array}{l}\text { cushaw } \\
\text { pumpkin, } \\
\text { Japanese pie } \\
\text { pumpkin }\end{array}$ \\
\hline Cucurbita moschata $^{\mathrm{c}}$ & 9 & 5 & $71 \%$ & $\begin{array}{l}\text { butternut } \\
\text { squash, } \\
\text { Seminole } \\
\text { pumpkin, }\end{array}$ \\
\hline
\end{tabular}




\begin{tabular}{|c|c|c|c|c|}
\hline & & & & $\begin{array}{l}\text { canned } \\
\text { pumpkin, } \\
\text { crookneck } \\
\text { squash }\end{array}$ \\
\hline Cucurbita ficifolia $^{\mathrm{c}}$ & 2 & 1 & - & $\begin{array}{l}\text { figleaf } \\
\text { gourd, } \\
\text { malabar } \\
\text { melon, Thai } \\
\text { melon }\end{array}$ \\
\hline Cucurbita cordata $^{\mathrm{w}}+$ & 2 & - & - & - \\
\hline Cucurbita digitata $^{\mathrm{w}}+$ & 2 & - & - & - \\
\hline $\begin{array}{l}\text { Cucurbita } \\
\text { ecuadorensis }^{\mathrm{w}}\end{array}$ & 2 & - & - & - \\
\hline $\begin{array}{l}\text { Cucurbita } \\
\text { foetidissima }{ }^{\mathrm{w}}{ }^{1}\end{array}$ & 6 & - & - & - \\
\hline $\begin{array}{l}\text { Cucurbita lundelliana } \\
\text { w,1 }\end{array}$ & 4 & - & - & - \\
\hline $\begin{array}{l}\text { Cucurbita } \\
\text { okeechobeensis ssp. } \\
\text { okeechobeensis }^{\mathrm{w}}, \text { C. } \\
\text { okeechobeensis ssp. } \\
\text { martinezii }^{\mathrm{w}, 1}\end{array}$ & 3 & - & - & - \\
\hline $\begin{array}{l}\text { Cucurbita palmata } \\
\mathrm{w}_{+} 1\end{array}$ & 2 & - & - & - \\
\hline $\begin{array}{l}\text { Cucurbita pedatifolia } \\
\mathrm{w}_{+}{ }^{1}\end{array}$ & 3 & - & - & - \\
\hline $\begin{array}{l}\text { Cucurbita radicans } \\
\mathrm{w}_{+}\end{array}$ & 0 & - & - & - \\
\hline \multicolumn{5}{|c|}{$\begin{array}{l}{ }^{C} \text { crop taxon }{ }^{w} \text { wild taxon }+ \text { Xerophytic perennial. Percent resolution calculated as nodes with }>50 \% \mathrm{BS} \\
\text { / possible nodes (two less than the number of tips) in the CA-ML tree. Species with - bifurcations are } \\
{ }^{1} \text { non-monophyletic or have only two accessions. }\end{array}$} \\
\hline
\end{tabular}




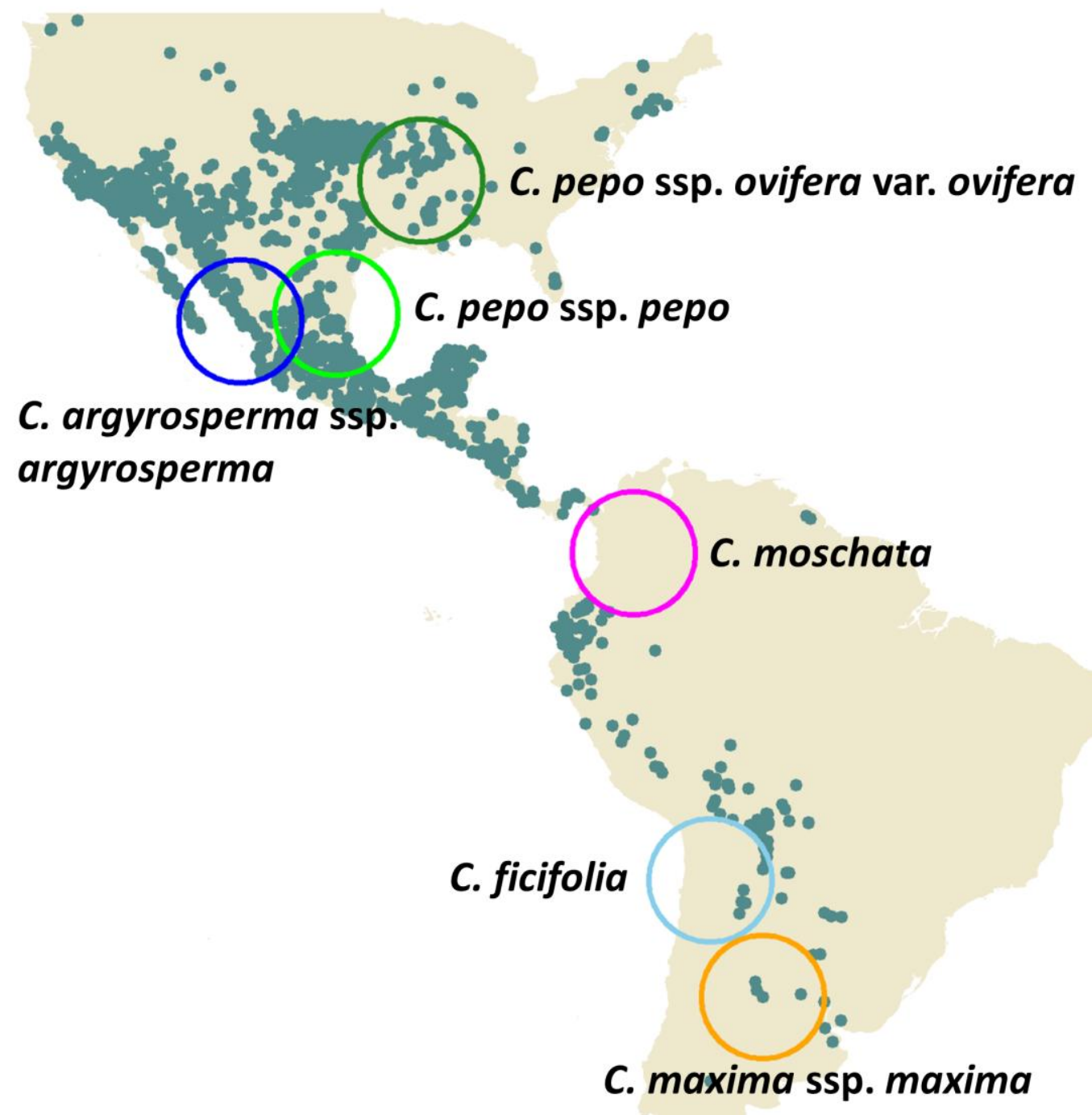

842

843 


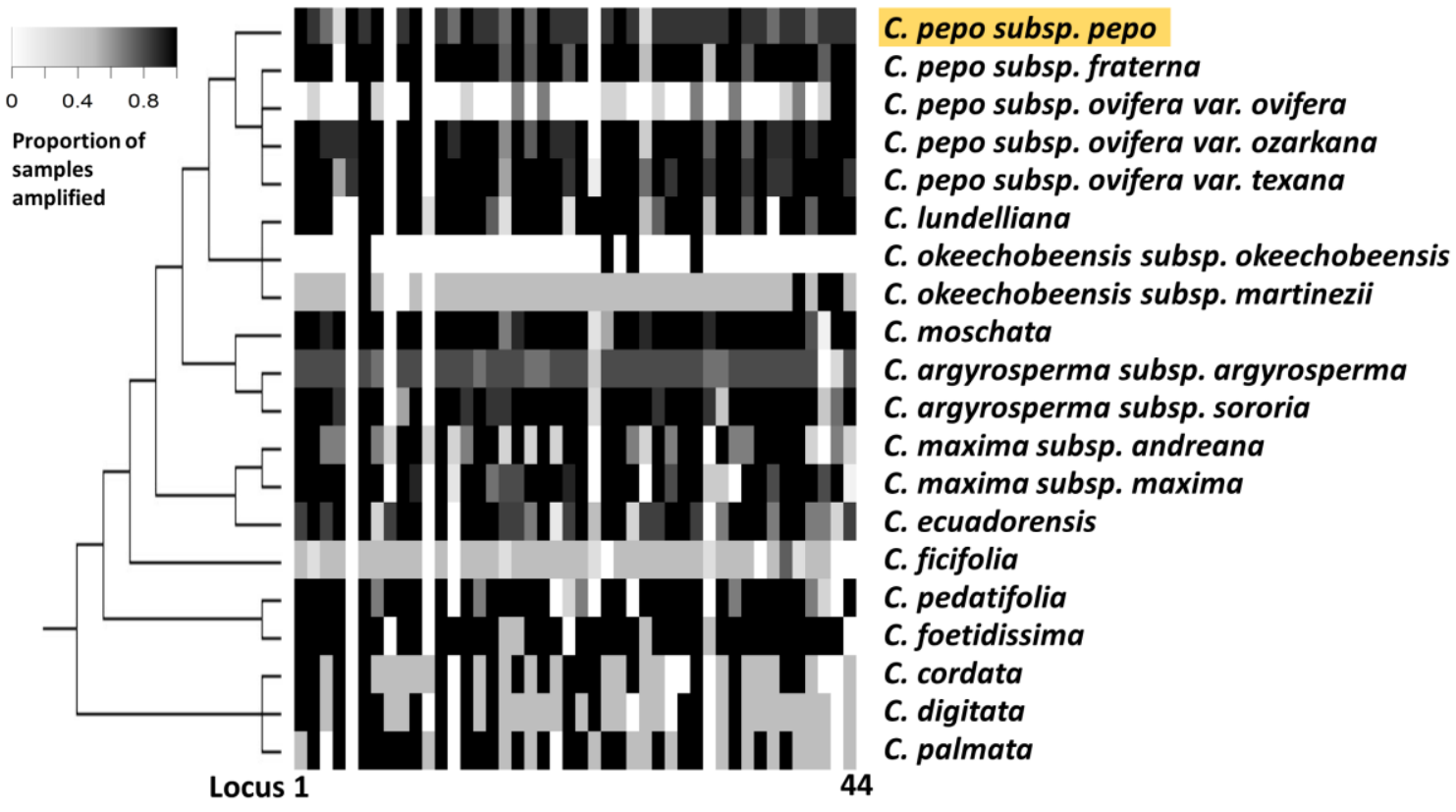




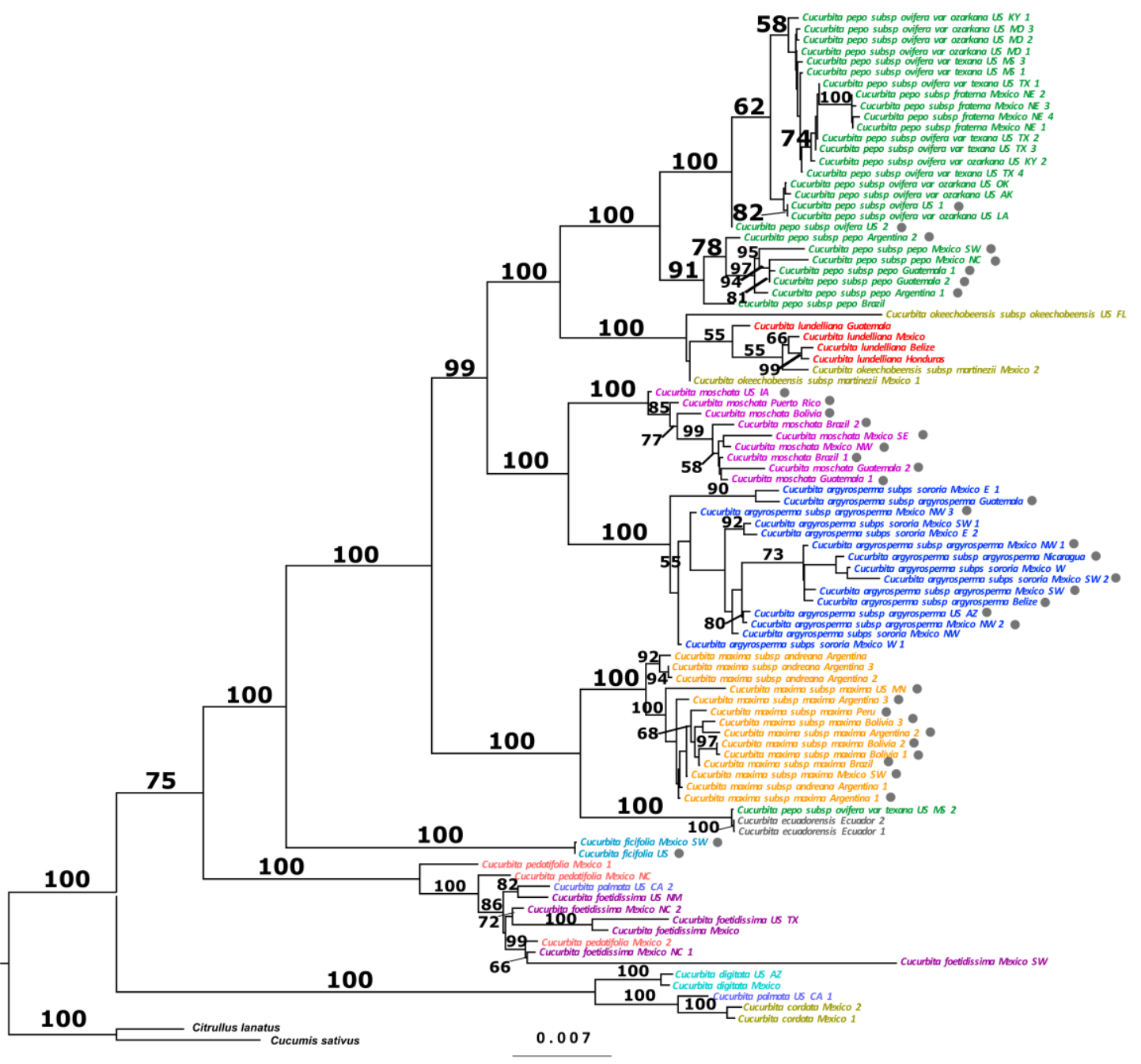

847 
a

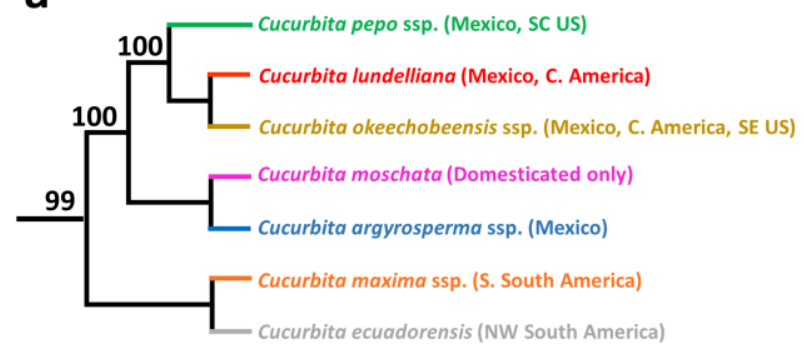

C

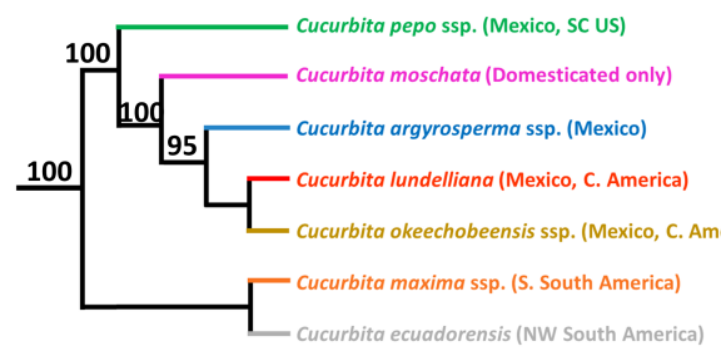

b

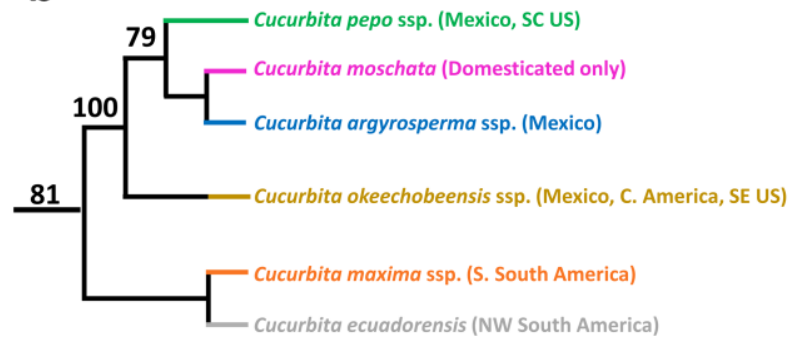

d

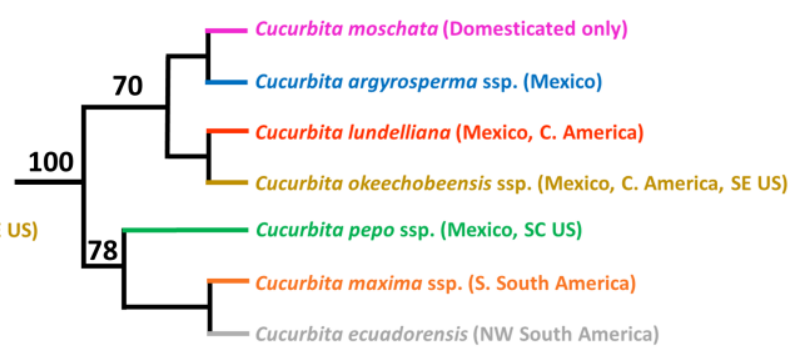

848 


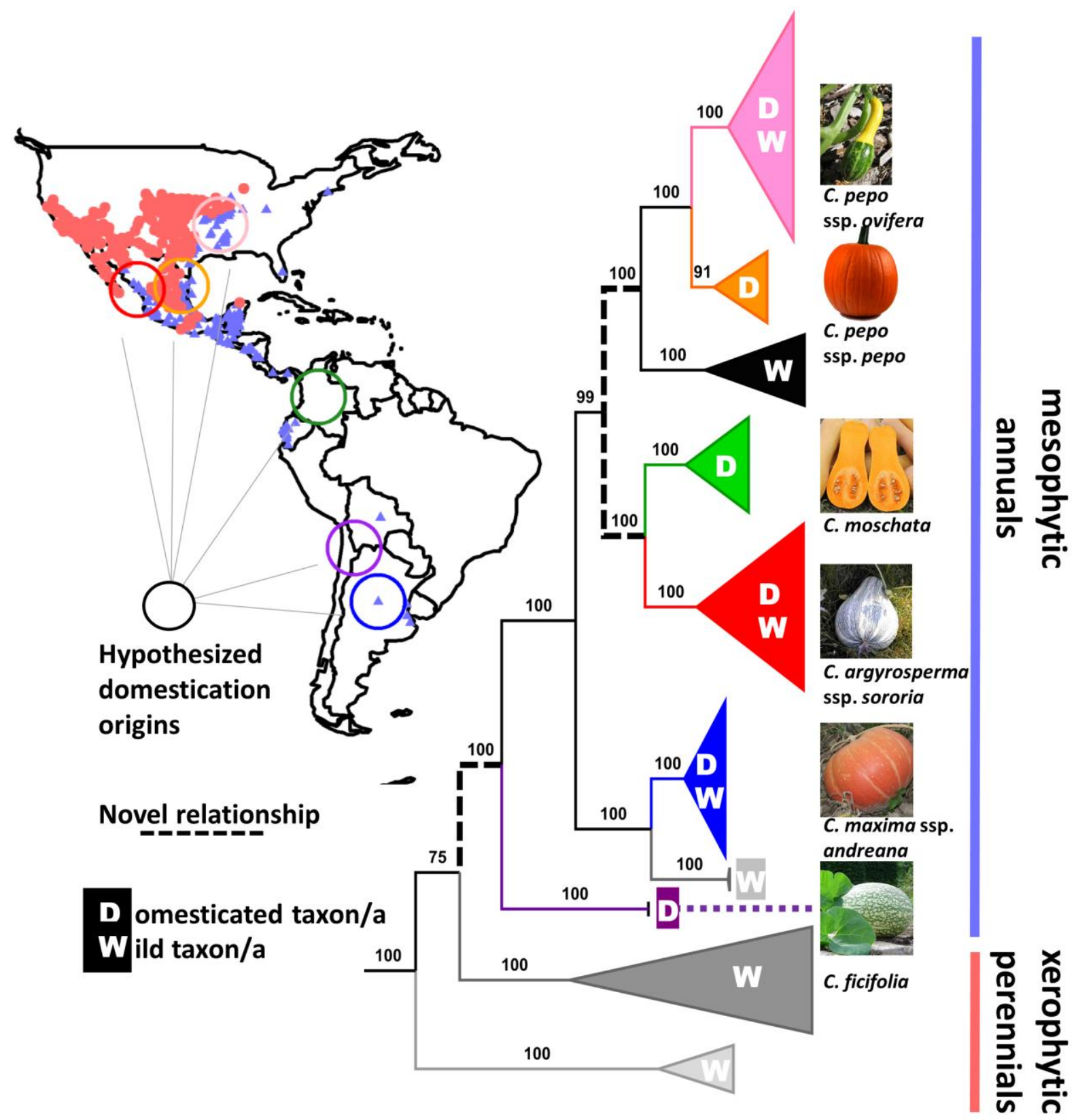

